\title{
Ritos, rituais e rotina: educação feminina nos colégios confessionais católicos no século XX
}

\section{Rites, Rituals and Routine: Feminine Education in Catholic Confessional Schools in the Twentieth Century}

\author{
Samara Mendes Araújo Silva*
}

\begin{abstract}
RESUMO
Ao participar do processo de formação das novas gerações, as instituições educacionais compartilharam também da responsabilidade pelo ensino dos demais códigos sociais dos quais se tornariam responsáveis, quer pela manutenção quer pela transformação, das dinâmicas da sociedade. Instituições de ensino resguardam compromissos, como oferecer conhecimentos técnico-científicos fundamentados e preceitos validados pela sociedade na qual estão inseridas. A sociedade brasileira partilhou tardiamente com a escola a tarefa de formação das novas gerações em razão do "modelo de desenvolvimento" adotado. Ao longo da História nacional, o acesso à educação formal é um direito recente, especialmente quando se refere à parcela feminina da população. Embora o acesso tenha sido tardio no Brasil, a educação formal estava disponível principalmente em colégios confessionais, em sua maioria católicos. Nos colégios católicos, no decorrer do século XX, incluíram-se na rotina dos neófitos, além dos conteúdos curriculares, atividades diversas para formar caráter, condutas sacra e intelectual, cuja execução delineou marcas nas memórias daqueles que as vivenciaram, ou, presenciaram esporadicamente. Utilizando fundamentos da História Cultural, recolhemos e analisamos fragmentos de memórias (relatos orais) e fotografias de ex-alunas que frequentaram os colégios savinianos (colégios que ensinavam somente ao gênero feminino) até a década de 1970, no Piauí. Analisamos elementos presentes em escolas católicas onde se verificou, a partir dos rituais esco-
\end{abstract}

* Universidade Federal do Paraná. Setor de Educação. Curitiba, Paraná, Brasil. E-mail: samara.mendes@ig.com.br. http://orcid.org/0000-0002-2340-015X. 
lares, a constituição de uma cultura escolar própria e a sua manutenção ao longo da trajetória de vida das egressas desses estabelecimentos escolares.

Palavras-chave: Educação feminina. Educação confessional. Educação católica. Cultura escolar. Rituais escolares.

\begin{abstract}
By sharing the process of formation of the new generations, the responsibility to teach other social codes to those who would become responsible for the maintenance and transformation of the dynamics of society was shared with educational institutions. Those institutions have commitments, such as offering technical and scientific knowledge based on principles validated by the society in which they are inserted. Brazilian society has belatedly shared with the school the task of training the new generations because of the "development model" adopted. Throughout the national history, access to formal education has only been considered a right recently, especially when it refers to the female portion of the population. Although full access was only achieved later, formal education in Brazil was available in a form, mainly in confessional schools (mostly catholic). In catholic schools during the twentieth century, in addition to the curricular content, there were diverse activities in the routine of the neophytes under their auspices to form character, and their sacred and intellectual conduct. Those activities delineated marks in the memories of those who experienced them or watched them sporadically. Using foundations of cultural history, we collected and analyzed fragments of memories (oral reports) and photographs of former students who attended the Saviniano schools (which taught only the feminine gender) until the 1970s, in Piauí, in order to analyze elements present in catholic schools and to demonstrate, from the school rituals, the constitution of school culture and its maintenance of along the life trajectory of the graduates.

Keywords: Feminine Education. Confessional Education. Catholic Education. School Culture. School Rituals.
\end{abstract}

\title{
Comentários iniciais
}

Em um de seus ensaios, o historiador Peter Burke (2009, p. 300) nos questiona sobre o "motivo do silêncio das pessoas", mais adiante esclarece que “[...] em muitas partes do mundo, religião e silêncio estão associados. Essa pode ser uma maneira de mostrar respeito pelos deuses". 
A afirmação de Burke corrobora as memórias de ex-alunas de colégios confessionais católicos brasileiros que afirmam repetidamente ser aquele "um lugar de silêncio", conforme recorda vividamente Josina Jacobino (2006):

[...] ninguém podia nem pisar mais forte pra não fazer zoada. Quem fosse subindo fazendo zoada tinha que descer devagarinho, todo mundo olhando [...] As escadas de madeira, ninguém podia fazer zoada. Quando faltava um professor, o professor atrasava, a gente ficava dentro da sala, trancada, sem dizer nada. Porque ficava uma Irmã no corredor, tipo uma inspetora, qualquer zoada, ela ia na sala, queria saber quem era. Então você tinha que ficar sentada, de cabeça baixa sem falar com ninguém. [...] Era a Irmã Maria do Amparo, a Irmã Porto, tudo ficava ali, controlando a gente. [...].

O silêncio e o disciplinamento das condutas são referências recorrentes para caracterização da educação oferecida nos estabelecimentos de ensino confessionais. Por meio de práticas educativas, em geral, esses estabelecimentos definiram trajetórias de vida e experiências sociais, fixaram comportamentos e incutiram concepções profundas naqueles que os frequentaram, quer enquanto discentes quer como docentes, posto que estivessem expostos e integrassem a cultura escolar daqueles espaços institucionais.

Lembremos, ainda, de que nossa sociedade ocidental, ao partilhar o processo de formação das novas gerações com as instituições educacionais, também compartilhou a tarefa de ensinar os códigos sociais aos que se tornariam responsáveis quer pela manutenção quer pela transformação das dinâmicas da sociedade. Cabendo, assim, às instituições de ensino resguardar os compromissos mútuos de: oferecer conhecimentos técnico-científicos fundamentados e preceitos (morais, culturais, sociais, religiosos etc.) validados pela sociedade na qual estão inseridas.

Os colégios confessionais católicos - que figuraram em maior número dentre os estabelecimentos de educação básica no território nacional até a primeira metade do século $\mathrm{XX}^{1}$ - se desincumbiram, desde os tempos coloniais no território brasileiro, de ofertar educação à população aqui residente. Embora a educação formal estivesse disponível no Brasil, em razão do "modelo de desenvolvimento" adotado, a maior parcela de nossa sociedade teve acesso

1 Para maiores informações e dados sobre a Educação Católica no Brasil, ver dentre outras a obra: MOURA, Pe. Laércio Dias de. A educação católica no Brasil. 2. ed. São Paulo: Edições Loyola, 2000. 
tardio ao processo de escolarização. Estes dados são mais precários quando se observa a parcela feminina da população para qual o acesso à educação formal é um direito recente.

O início da educação formal das mulheres no Brasil, em fins do século XIX, foi uma atribuição legada às escolas confessionais (não restrito aos estabelecimentos católicos, ainda que estes figurassem em maior quantidade e atendessem o maior número de educandas naquele momento da história da educação brasileira). O objetivo era integrá-las à formação do "novo cidadão", articulado com novos princípios patrióticos, morais, científicos e religiosos, cuja finalidade era que se tornassem esposas e mães adequadas e eficientes ao desenvolvimento da nação.

Considerando a História da Educação Brasileira, pode-se afirmar que a sociedade partilhou tardiamente com a escola a tarefa de formação das novas gerações, especialmente quando se refere às mulheres. Porém, quando passou a realizar tal inserção, as instituições foram eficientes em dotar a todos os que ali estavam de uma cultura considerada adequada, tornando-os portadores e difusores dos conhecimentos e preceitos difundidos no ambiente escolar.

Isso acontece porque as escolas dispõem de práticas e comportamentos próprios, mesmo que se coadunem com os preceitos da sociedade da qual evitam se misturar; portanto, a:

cultura escolar não pode ser estudada sem a análise precisa das relações conflituosas ou pacíficas que ela mantém, a cada período de sua história, com o conjunto das culturas que lhe são contemporâneas: cultura religiosa, cultura política ou cultura popular. Para ser breve, poder-se-ia descrever a cultura escolar como um conjunto de normas que definem conhecimentos a ensinar e condutas a inculcar, e um conjunto de práticas que permitem a transmissão desses conhecimentos e a incorporação desses comportamentos; normas e práticas coordenadas a finalidades que podem variar segundo as épocas (finalidades religiosas, sociopolíticas ou simplesmente de socialização). Normas e práticas não podem ser analisadas sem se levar em conta o corpo profissional dos agentes que são chamados a obedecer a essas ordens e, portanto, a utilizar dispositivos pedagógicos encarregados de facilitar sua aplicação, a saber, os professores primários e os demais professores. Mas, para além dos limites da escola, pode-se buscar identificar, em um sentido mais amplo, modos de pensar e de agir largamente difundidos no interior de nossas sociedades, modos que não concebem a aquisição de conhecimentos e de habilidades senão por intermédio de processos formais de escolarização: aqui se encontra a escalada dos dispositivos propostos pela schooled society que 
seria preciso analisar; nova religião com seus mitos e seus ritos contra a qual Ivan Illich se levantou, com vigor, há mais de vinte anos. (JULIA, 2001, p. 10-11, grifo nosso).

Conforme explicita Julia (2001), a cultura escolar ultrapassa os limites da escola; quando abordamos os colégios confessionais católicos, esse aspecto se torna mais notável. Para exemplificar, retomemos os fragmentos das memórias, citados no início do texto, da ex-aluna Josina Jacobina que afirmou que aprendeu a andar e a subir escadas em silêncio devido aos anos de estudo no Colégio Sagrado Coração de Jesus² .

Além dos conteúdos curriculares, os colégios católicos, no decorrer do século $\mathrm{XX}$, incluíram atividades diversas na rotina dos neófitos sob seus auspícios, como alguns ritos utilizados para a formação intelectual (científico), moral, religiosa e sacra, bem como para a do caráter, da conduta etc. O desenvolvimento e a execução dessas práticas educativas delinearam marcas na formação e nas memórias daqueles que as vivenciaram diretamente, ou indiretamente, ou ainda as presenciaram esporadicamente como espectadores, visto que não raro havia convidados externos a esses eventos.

Analisamos alguns momentos da rotina, ritos e rituais escolares durante o século XX de dois colégios católicos (Teresina e Parnaíba ${ }^{3}$ ) que ensinavam somente ao gênero feminino, até a década de 1970, no Piauí. Desde a fundação, os colégios estão sob a direção da Congregação das Irmãs dos Pobres de Santa Catarina de Sena (Irmãs Savinianas), demonstrando a manutenção de aspectos da cultura escolar ao longo da trajetória de vida das egressas desses estabelecimentos escolares.

Para investigar elementos presentes da cultura escolar de escolas católicas, utilizamos os fundamentos da História Cultural, recolhemos e inquirimos os fragmentos de memórias (relatos orais) e fotografias de ex-alunas que frequentaram os Colégios Savinianos do século XX até a década de 1970, período em que as escolas aceitavam matrículas somente de mulheres.

2 Colégio fundado em 1906 na cidade de Teresina, Piauí, pela Congregação das Irmãs dos Pobres de Santa Catarina de Sena, o qual permanece até atualidade sob a direção da mesma ordem religiosa.

3 O colégio de Teresina foi fundado em 1906 e é denominado Colégio Sagrado Coração de Jesus. O Colégio de Parnaíba, inaugurado em 1907, tem o nome de Colégio Nossa Senhora das Graças. 


\section{Rotina nos colégios católicos}

As instituições confessionais estabeleciam a rotina para os escolares, em geral, nos "Estatutos e Regras do Colégio", cujo conteúdo era apresentado para os pais e os próprios estudantes, inicialmente em audiência privada com a direção da escola e, posteriormente, no decorrer do ano letivo, em preleções públicas no Parlatório e no púlpito da capela.

Os Colégios Savinianos piauienses elaboraram ainda em 1906 os "Estatutos e Regras Paras as Educandas do Collegio Dirigidos pelas Irmãs dos Pobres de Santa Catharina de Sena". No documento "materializam o pensamento vigente naquelas instituições sobre variadas temáticas [...]" (SILVA, 2010, p. 136), desde o asseio e o vestuário das alunas externas e internas, passando pelos horários de aulas e conteúdos básicos a serem ministrados nas aulas de catecismo e práticas de prendas domésticas.

Inquirindo os primeiros "Estatutos" dos Colégios Savinianos piauienses, encontramos nos artigos I e III as seguintes afirmações:

[...] todos conhecem a importância da instrucção religiosa para formar o coração a prática dos princípios da fé e da moral catholica; por isso, além dos outros estudos acima mencionados, cada dia haverá neste estabelecimento a prática e o ensino destes princípios [...] As prendas compreendem: costura, pontos de marca, cerzir em meias ou panos etc. [...]. (COLÉGIO SAGRADO CORAÇÃO DE JESUS, s.d., p. 2).

Observando os regimentos escolares da década de 1960 do Colégio de Parnaíba, este informa que:

[...] Tem por finalidade educar e instruir a mocidade brasileira, nesta região do território nacional e formar-lhe o espírito sob os princípios da moral cristã.

Com o objetivo claro de cooperar com o progresso intelectual, moral e material da Pátria brasileira, este estabelecimento de ensino, vem trabalhando com zelo, carinho, perseverança, há mais de 50 anos na formação da juventude feminina. [...]

Compete ao Professor:

e) Manter a ordem e disciplina entre as alunas durante o tempo de aula, não se ocupando de assuntos alheios ou estranhos às lições. Não sendo permitido palestras de caráter mundano. [...] 
f) Colaborar cuidadosamente pela educação moral das alunas ajudando no que pode à Diretoria, zelando assim pelo nome do Estabelecimento. (GINÁSIO NOSSA SENHORA DAS GRAÇAS, 1962, p. 01, 03).

Reconhecemos que, na educação empreendida naqueles estabelecimentos de ensino, ainda que ocorressem alterações nos estatutos e regimentos ao longo das sete décadas em que os colégios atendiam exclusivamente mulheres, as Irmãs prezavam pela educação moral, pelo ensino da religião católica e pelo conteúdo das "Prendas" a serem ensinados às alunas.

A prática da oração era uma constante no cotidiano das alunas dos colégios católicos, conforme lembrou a ex-aluna Eva Evangelista Leal (2006):

Eva Evangelista Leal: [...] Rezava... [...] Rezávamos no pátio é, não, mas no pátio geralmente era o hino Nacional. Aí antes de cada aula a gente rezava, ficava de pé e rezávamos todos.

Pergunta: Tinha quatro aulas por dia e antes de cada aula...

Eva Evangelista Leal: [...] Antes de cada aula rezava.

Pergunta: Rezavam muito?

Eva Evangelista Leal: [...] É, mas ninguém nem sentia. Achava normal.

Executar orações no ambiente escolar para cumprir as determinações dos Estatutos tornou-se uma prática habitual dessas mulheres, mesmo quando deixaram o espaço escolar. Algumas, após passados vários anos da conclusão dos estudos no Colégio Saviniano, mantinham o hábito, como a ex-aluna Lili Leite, por exemplo, que frequentou o internato em Teresina, no período de 1944 a 1948. Ela declara que até hoje não consegue iniciar nem terminar o seu dia sem rezar um terço, pois era assim que fazia no tempo do colégio.

Relembrando os momentos de orações (Figura 1), outra ex-aluna, Graça Sá, contou-nos que:

A hora era muita rígida. A aula começava 7 , a gente tinha que chegar pelo menos 15 min antes de 7 h, porque a gente entrava, ia pra Capela pra rezar o terço, depois do terço que ia pra sala de aula (Sim, e a história de quem não rezava o terço direito?) Quem não rezava o terço, recebia um castigo. Eu pelo menos uma vez, peguei o castigo de rezar 3 terços. Eu e mais a turma todinha (num re...) [...]. 
FIGURA 1 - ALUNAS REZANDO NA CAPELA DO COLÉGIO SAGRADO CORAÇÃO DE JESUS, TERESINA/PI

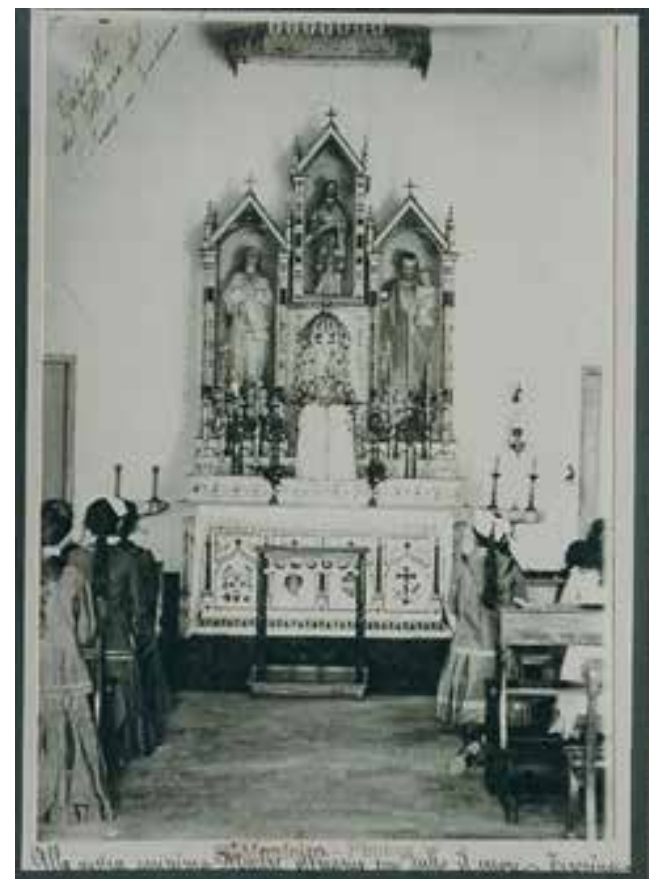

FONTE: Secretaria do Colégio Sagrado Coração de Jesus - Teresina/PI.

A rotina das alunas dos colégios savinianos era constituída basicamente por aulas entremeadas por orações. O propósito principal da educação feminina organizada até a primeira metade do século XX era atender a "demanda por mulheres instruídas para cumprimento da tarefa de educar os cidadãos da nação em formação" e também mantê-las defensoras e vinculadas ao cristianismo.

\section{Ritos nos colégios católicos}

Para demarcar a passagem, o tempo ou celebrar os eventos nos colégios confessionais, foram instituídos uma série de Ritos. No entanto, consultar um dicionário de língua portuguesa pouco ou nada nos auxiliará a compreender a 
importância dos significados dessas cerimônias ou mesmo dos objetos que as materializavam, por vezes, simples, quando observadas por um espectador estranho ao todo espectro simbólico resguardado pela cultura escolar engendrada pelas colégios savinianos e seus sujeitos. Posto que no Dicionário de Língua Portuguesa conste a exígua definição de que Rito seria um "conjunto das cerimônias que usualmente se praticam numa religião, numa seita etc.; liturgia. Exs.: r. católico; r. do candomblé.” (RITO, 2009, não p.).

Buscando em outras fontes, encontraremos que

Segundo o linguista Émile Benveniste, a palavra 'rito' teria vindo de ritus, significa 'ordem prescrita', termo associado a formas gregas tais como artus 'ordenação', ararisko 'harmonizar', 'adaptar' e arthmos, que evoca o 'laço', a 'junção'. Junto com a raiz ar que deriva do indo-europeu védico (rta, arta), a etimologia remete essa análise à ordem do cosmo, à ordem das relações entre os deuses e os homens, à ordem dos homens entre si. (SEGALEN, 2002, p. 17, grifo nosso).

Para compreender os Ritos que se desenrolam e adquirem significados múltiplos para aqueles sujeitos que os vivenciaram nos colégios católicos, devemos compreendê-los enquanto "integrante das relações dos homens entre si"; pois

[...] para compreender um rito, uma instituição ou uma técnica, não se deve extraí-lo arbitrariamente do conjunto cerimonial, jurídico ou tecnológico de que fez parte; ao contrário, é preciso sempre considerar cada elemento desse conjunto em suas relações com todos os outros elementos. (SEGALEN, 2002, p. 46).

Os ritos escolares têm significados múltiplos e díspares. Cumprir determinado momento da ritualista escolar e obter êxito tornam públicas à sociedade as expectativas em torno do sujeito escolar e, também, o faz ser reconhecido como diferente ante os demais que frequentam a instituição, mas que não se submeteram ao rito ou o fizeram e falharam. Para o sujeito recém-ritualizado, em contrapartida, há ampliação de exigências para que cumpra novas metas e padrões sociais, para que alcance o mais breve outro patamar na esfera social.

$\mathrm{Na}$ organização do ano letivo saviniano, um dos ritos mais aguardado pelas alunas e preservado até os dias atuais pelos colégios da congregação no 
Piauí era a fotografia de final de ano da turma (Figuras 2 e 3 ). A diretoria dos colégios contratava um fotógrafo profissional para realizar o registro da imagem de todas as turmas matriculadas a cada ano letivo.

Durante anos seguidos o profissional responsável por este registro em Teresina foi Guilherme Müller ${ }^{4}$, segundo nos informou a ex-aluna Erice Rodrigues (2008, p. 8).: "tinha o Müller que era o fotógrafo famoso que tinha lá, que se encarregou de tirar essas fotografias".

\section{FIGURAS 2 E 3 -FOTOS DE CONCLUSÃO DE ANO LETIVO, COLÉGIO SAGRA- DO CORAÇÃO DE JESUS - TERESINA/PI}

ANO 1961

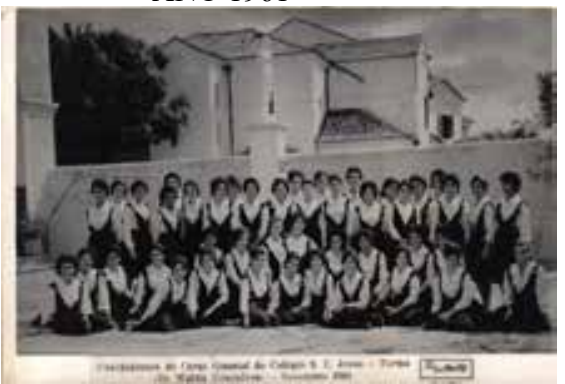

ANO 1963

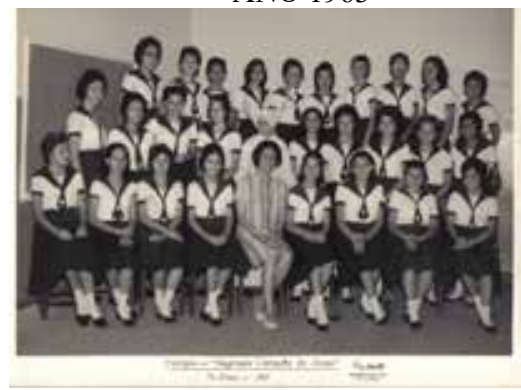

FONTE: acervo pessoal de Erice de Moura Rodrigues, 2008.

As turmas de concludentes de cursos, em geral, escolhiam os nomes de professores para denominar-se como forma de homenagem. Tal como fizeram em 1961 as formandas do Curso Ginasial que escolheram o Prof. Waldir Gonçalves $^{5}$ (História) como nome da Turma (Figura 2 - ano 1961). Para aquelas turmas que não estavam em terminalidade de cursos era comum ocorrer a escolha de professores ou religiosas, ou ambos, para estarem presentes nas fotografias comemorativas de encerramento do ano letivo. A presença de uma

4 Guilherme Müller era fotógrafo profissional e prestou serviços para o Governo do Estado do Piauí no período de 1940 a 1960. Para atender a demanda do Colégio Sagrado Coração de Jesus/Teresina por fotografias ao final de cada ano letivo e em ocasiões especiais, montou um estúdio fotográfico ao lado do salão de beleza administrado por suas filhas, frequentado, quase que exclusivamente, pelas alunas das freiras Catarinas.

5 O professor Waldir Gonçalves, segundo os registros do Colégio, foi contratado em 1938. Foi o primeiro presidente de honra do Grêmio Cultural Santa Catarina de Sena, fundado em 1944, no Colégio de Teresina. Em 1976, por ocasião das comemorações do aniversário de 70 anos do Colégio, foi escolhido para fazer o discurso de abertura da solenidade que encerrou tais festividades no dia 24 de outubro, no Teatro 4 de setembro. Este docente foi homenageado em repetidas ocasiões para designar turmas de formandas do Colégio. 
docente e uma religiosa, ladeadas pelas alunas, foi registrada na fotografia do encerramento do ano letivo da Turma de 1963 (Figura 3 - ano 1963) e guardada pela ex-aluna Erice Rodrigues.

As fotos das turmas eram registradas em diferentes espaços dos colégios, como se pode observar nas Figuras 2, 3 e 4. Após a década de 1950, as escadarias e as entradas principais tornaram-se os principais locais para o registro oficial das turmas savinianas.

FIGURAS 4 E 5 - FOTO DE CONCLUSÃO DO ANO LETIVO 1964, COLÉGIO SAGRADO CORAÇÃO DE JESUS, TERESINA/PI, E VERSO DA FOTOGRAFIA

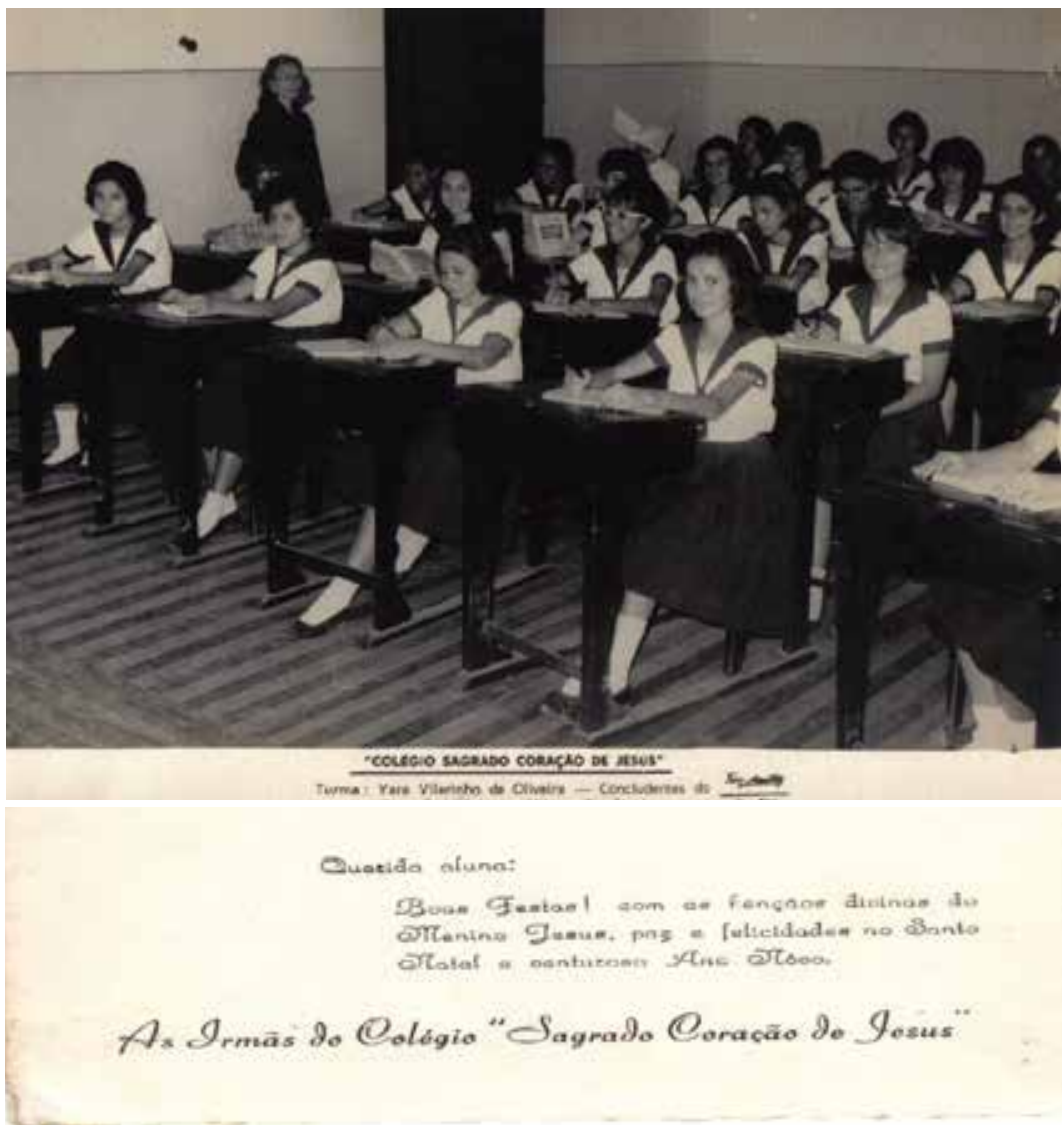

FONTE: acervo pessoal de Erice de Moura Rodrigues, 2008. 
No contexto, as atividades sacras do cotidiano dos colégios savinianos culminavam com as associações religiosas existentes nos colégios: Apostolado da Oração e União Pia das Filhas de Maria, aos quais nem todas as alunas poderiam pertencer, segundo nos informou Lili Leite, embora todas pudessem se inscrever.

Colégios das Irmãs mantinham as Associações Religiosas: Pia União das Filhas de Maria (fundado em Teresina em 15 de junho de 1907 e em Parnaíba em 10 de maio de 1908), Apostolado da Oração e Congregação dos Santos Anjos (fundada em 1925), todas tendo como integrantes alunas e ex-alunas dos Colégios. Contudo, dentre estas Associações, as Filhas de Maria e o Apostolado da Oração acabaram por merecer maior atenção das alunas quanto das religiosas, posto que estas duas Associações corroborassem com, mais amplitude, os objetivos e princípios da educação católica para mulheres posto que encorajasse as alunas a "prática da verdadeira piedade e a fuga das vaidades e dos divertimentos mundanos". (COLÉGIO SAGRADO CORAÇÃO DE JESUS, 1933, p. 28). A Pia União das Filhas de Maria ${ }^{6}$ nos Colégios das Irmãs foi fundada pelo Bispo Dom Joaquim ${ }^{7}$ e o mesmo presidiu as cerimônias de recepção das primeiras alunas savinianas que se tornaram Filhas de Maria - sendo 6 associadas, 15 aspirantes e 18 postulantes. [...] A Pia União de Parnaíba iniciou com 28 associadas, sendo 24 aspirantes e quatro Filhas de Maria. Em novembro de 1908, já havia o registro de 46 membros. (SILVA, 2010, p. 205-206).

A medalha da Pia União de Maria tem em uma face a efígie de Nossa Senhora das Graças em gesto de acolhimento de suas filhas que são apresentadas por Santa Inês, circundada pela inscrição em latim: MATER, TVOS OCVLOS ADNOS CONVERTE (que em tradução literal significa "Mãe, põe teus olhos sobre nós"). E, na outra face, temos o monograma de Maria sobre os Corações de Jesus e Maria cercado por doze estrelas, as quais são circundadas pela

6 “A Pia União das Filhas de Maria é uma piedosa associação de donzelas que se colocam debaixo do estandarte da Virgem Imaculada e de Santa Inês, Virgem Mártir, para melhor e mais facilmente cumprirem os deveres de seu estado." (ROWER, 1946, p. 13). Na Europa, Santa Inês é conhecida também como Santa Agnes. No Brasil, a primeira Associação das Filhas de Maria foi criada em fins do século XIX, em São Paulo, na cidade de Itu, pelas Irmãs de São José e tinha como associadas às alunas do Colégio Nossa Senhora do Patrocínio.

7 Dom Joaquim foi o primeiro bispo da Diocese do Piauí. 

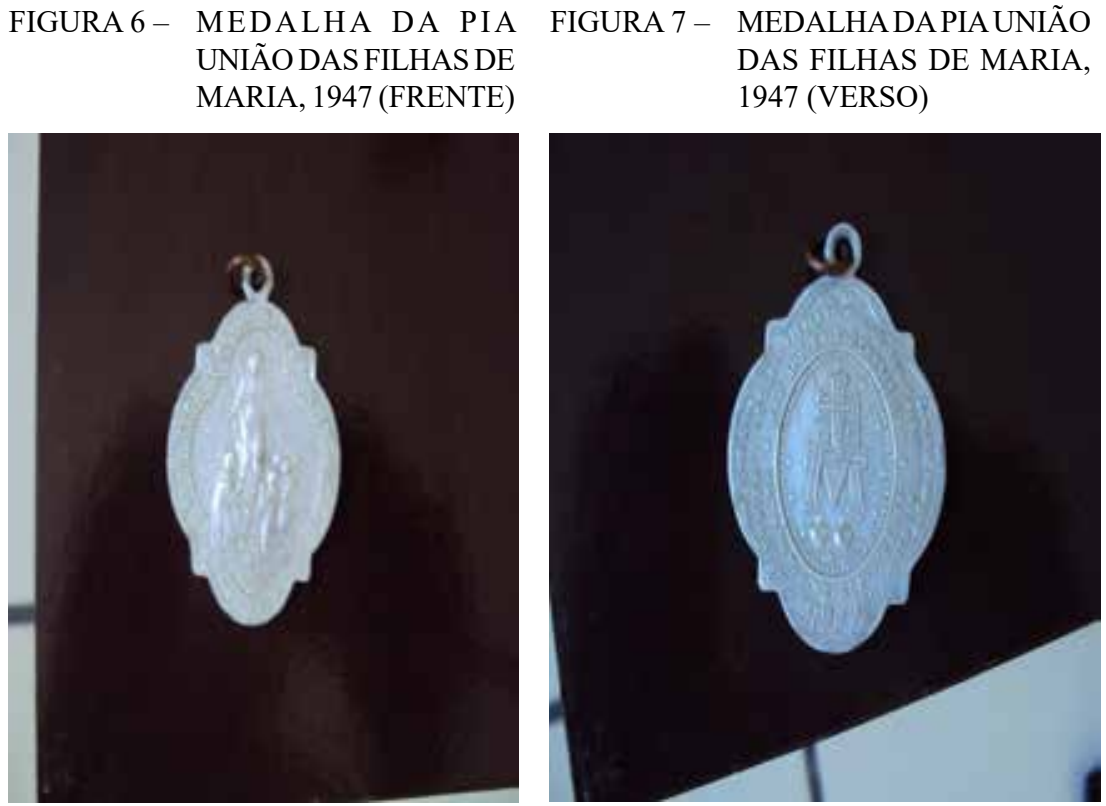

FONTE: acervo pessoal de Alexandrina (Lili) Leite de Castro, 2010.

inscrição em latim: SODALITAS FILIARUM MARIAE SUB PATROCINIO B. V. IMMACULATAE ET S. AGNETIS V. M. ROMANAM AD S. AGN. PIUS IX PRIMARIAM DIXT INDULGENTIIS DITAVIT (que em tradução literal significa "Solidárias Filhas de Maria sob a proteção da Imaculada Santa Inês, Virgem Romana, e do Santo Papa Pio IX, recebem a primária indulgência”). (SILVA, 2010, p. 206).

Tornar-se uma Filha de Maria, além de símbolo de devoção cristã, no âmbito dos colégios católicos, era representação de distinção e, no seio da Igreja, a recepção da indulgência plenária ${ }^{8}$. Assim, para as alunas e ex-alunas, ingressar na associação significava receber reconhecimento em diferentes instâncias da sociedade: mundana e religiosa.

8 De acordo com o Catecismo da Igreja Católica, uma indulgência é "A remissão, diante de Deus, da pena temporal devida pelos pecados já perdoados quanto à culpa (remissão), que o fiel bem-disposto obtém, em condições determinadas, pela intervenção da Igreja que, como dispensadora da redenção, distribui e aplica por sua autoridade o tesouro das satisfações (isto é, dos méritos) de Cristo e dos santos. A indulgência é parcial se remover parte da pena temporal devida pelo pecado, ou plenária, se remover toda a pena." As Filhas de Maria recebem, ao ingressar na Associação, a indulgência plena de seus pecados. 
Muito próxima à União Pia das Filhas de Maria figurava o Apostolado da Oração", por vezes, até existindo rivalidades entre as associadas, posto que "as alunas desejavam participar das duas entidades religiosas e, algumas vezes, não conseguiam sucesso na admissão" (SILVA, 2010, p. 211).

O símbolo de distinção das associadas ao Apostolado da Oração eram as insígnias do Sagrado Coração de Jesus e a cruz com a imagem do Sagrado Coração de Jesus [Figura 8] - fixas a uma fita vermelha-, o diploma de Zeladora do Coração de Jesus e o manual da Associação. Havia, também, uma cerimônia religiosa para a recepção das novas Zeladoras do Coração de Jesus, na qual se fazia a benção das fitas, as postulantes faziam sua consagração e votos de devoção ao Sagrado Coração de Jesus e ao Sagrado Coração de Maria. (SILVA, 2010, p. 212).

\section{FIGURA 8 - INSÍGNIAS DO SAGRADO CORAÇÃO DE JESUS E CRUZ COM A IMAGEM DO SAGRADO CORAÇÃO DE JESUS}

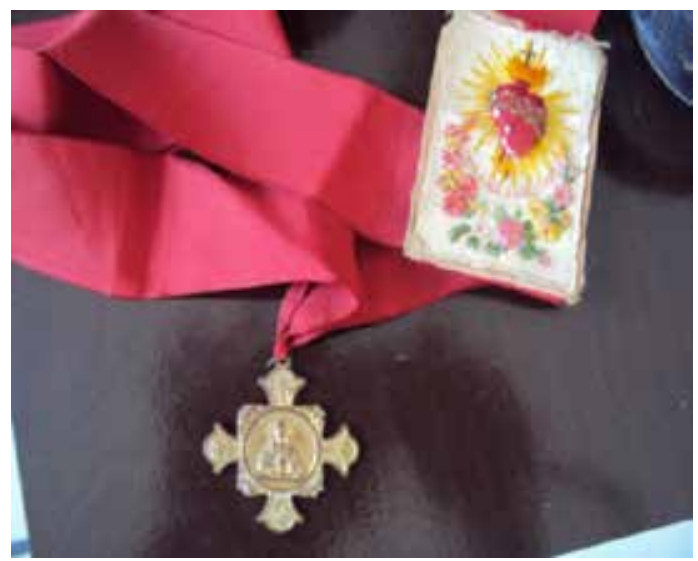

FONTE: acervo pessoal de Alexandrina (Lili) Leite de Castro, 2010.

No cotidiano das alunas savinianas, foram alocadas uma miríade de ritos

9 Associação do Apostolado da Oração do Coração de Jesus foi criada no Brasil em 1871, pelo padre jesuíta Bartolomeu Taddei com o objetivo de aproximar as almas do Coração de Jesus e da eucaristia. Em julho de 1899, o Papa Leão XIII reconheceu a importância da associação e aprovou os estatutos, quais foram remodelados na década de 1950, e o Papa Pio XII concedeu aprovação em 28 de outubro de 1951. 
que contribuíram para reiterar e orientá-las tanto na direção dos preceitos cristãos quanto da moralidade patriarcal, ainda pujante no século XX. Nessas os papéis dos gêneros são visivelmente compartimentados, segmentando as atividades e espaços sociais, bem como as atribuições socioeconômicas e culturais.

\section{Rituais nos colégios católicos}

O espaço escolar confessional proporcionado pela (con)vivência entre os diferentes e divergentes sujeitos sociais imersos e inseridos neste, bem como por aqueles que ali transitam extemporaneamente - mas que exercem interferências em menor e/ou maior proporcionalidade - produz cultura(s). Esta se manifesta de modo vivaz e constantemente é (retro)alimentada por e através dos mesmos sujeitos que a forjam.

A cultura escolar projeta-se na sociedade por meio de múltiplos e diferentes aspectos e pode ser expressa tanto em práticas e saberes (imaterialidade) quanto em objetos, mobiliários, edificações etc. (materialidade).

Considerando essa perspectiva, os rituais escolares dos colégios católicos são estratégias eficientes de difusão da cultura escolar e, consequente, dos valores propostos por estas instituições. Pois inseridos no contexto dos colégios católicos, atuam tanto no ambiente intra quanto extraescolar difundindo os valores e preceitos concomitantemente para sujeitos público interno (comunidade escolar) e a sociedade não escolar, promovendo a ampliação dos objetivos a atingir e público alvo.

Nesse ponto é importante compreender o que se constitui como sendo um Ritual:

Um conjunto de atos formalizados, expressivos, portadores de uma dimensão simbólica. O rito é caracterizado por uma configuração espaço-temporal específica, pelo recurso a uma série de objetos, por sistemas de linguagens e comportamentos específicos e por signos emblemáticos cujo sentido codificado constitui um dos bens comuns de um grupo. Essa é uma definição que: retém critérios morfológicos; insiste na dimensão coletiva, na medida em que o ritual faz sentido para todos que dele compartilham; reconhece que essas manifestações têm um campo específico para marcar rupturas e descontinuidades, momentos críticos (passagem) tanto em tempos individuais quanto em tempos sociais; e prioriza a sua eficácia social. O ritual faz sentido, visto que ordena a 
desordem, atribui sentido ao acidental e ao incompreensível, confere aos atores sociais os meios para dominar o mal, o tempo e as relações sociais. Sua essência é misturar o tempo individual e coletivo. Definidos em suas propriedades morfológicas e através de sua eficácia social, os ritos também se caracterizam por ações simbólicas manifestadas por emblemas sensíveis, materiais e corporais. Enquanto conjuntos fortemente institucionalizados ou efervescentes - quer regulem situações de adesão comum a valores, quer funcionem como reguladores de conflitos interpessoais -, os ritos devem ser considerados sempre como um conjunto de condutas individuais e coletivas relativamente codificadas, com suporte corporal (verbal, gestual e de postural), caráter repetitivo e forte carga simbólica para atores e testemunhas. Tais condutas são fundadas numa adesão mental - de que o ator eventual não tem consciência - a valores relativos de escolhas sociais consideradas importantes e cuja eficácia esperada não advém de uma lógica puramente empírica que se esgotaria na instrumentalidade técnica da ligação causa-efeito. Finalmente, o ritual se reconhece como fruto de uma aprendizagem, implicando, por conseguinte, a continuidade das gerações, dos grupos etários ou dos grupos sociais dentro dos quais ele se produz. Através de sua dimensão simbólica, 'o rito é uma linguagem eficaz na medida em que atua sobre a realidade social', decorrendo daí que o rito não se pode fazer de qualquer maneira, precisando apoiar-se em símbolos reconhecidos pela coletividade. (SEGALEN, 2002, p. 31-32, grifo nosso).

Tomando estes parâmetros como ponto de partida para verificar a cultura escolar nos colégios católicos, podemos afirmar que

A trajetória dos sujeitos escolares é impregnada por uma diversidade de rituais, estes progressivamente sofreram alterações nos significados e momentos de realização, contudo preservaram a riqueza do simbolismo, a profusão de sentidos e a produção de bens materiais e imateriais, sendo capazes de evocar e engendrar em todos aqueles que o vivenciaram ou mesmo têm contato com suas "relíquias" uma variedade de sentimentos e revolver as memórias. (SILVA, 2018, p. 03).

Assim, para as ex-alunas savinianas e mesmo para a direção dos colégios, os rituais de eucaristia e formatura(s) eram os mais aguardados e destacavam-se dos demais. A Celebração da $1^{\mathrm{a}}$ eucaristia das alunas era incluída no Calendário de Atividades Escolar (Fig. 9), evento que acontece até a atualidade. As alunas 
eram preparadas para este evento no próprio Colégio: “as aulas de Catecismo eram ministradas no próprio Colégio, no horário inverso ao que as alunas estudavam." (SILVA, 2010, p. 179).

$\mathrm{O}$ destaque para a $1^{\mathrm{a}}$ eucaristia não se resume a um evento meramente religioso, embora as religiosas savinianas destaquem e ensinem às alunas que irão "receber Cristo pela primeira vez" "o respeito e a prática dos sacramentos cristãos [devam ser] são tomados [...] como imprescindível aos bons católicos" (SILVA, 2010, p. 179). Este ritual acontece, não raro, fora das instalações dos colégios, nas igrejas matrizes das cidades em razão da grande quantidade de alunas para comungar neste dia. De modo que este fato se transformou em uma excelente ocasião para os colégios demonstrarem publicamente - sem ostentação nem forçosamente - a eficiência da educação ofertada às mulheres ali matriculadas.

\section{FIGURA 9 - PRIMEIRA EUCARISTIA DAS ALUNAS DO COLÉGIO SAGRADO CORAÇÃO DE JESUS, TERESINA/PI}

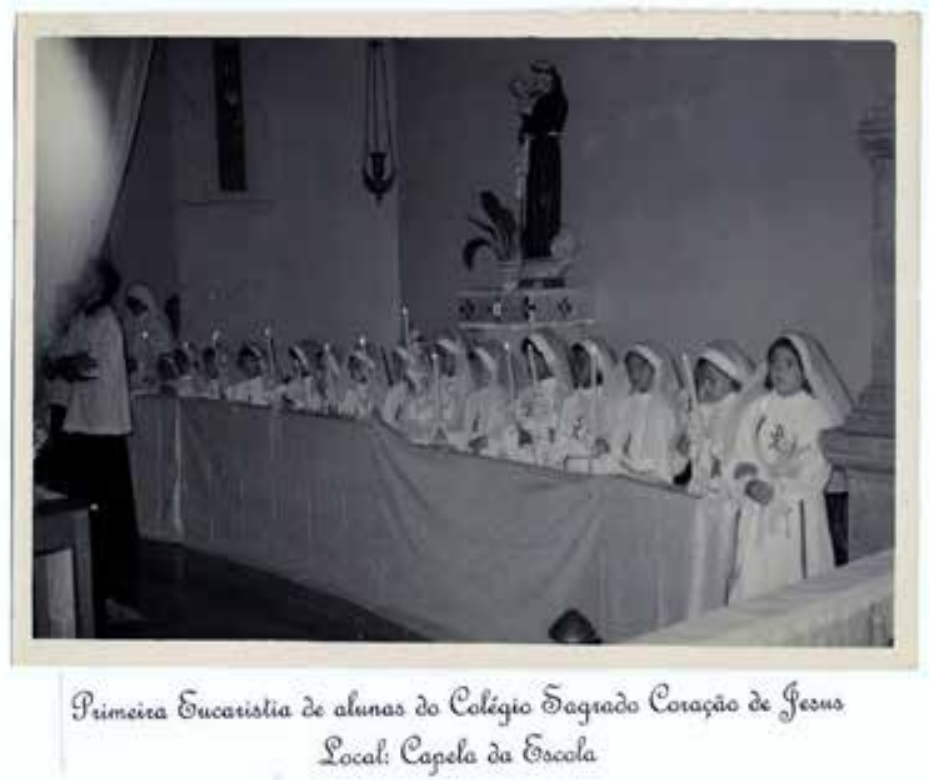

FONTE: Secretaria do Colégio Sagrado Coração de Jesus - Teresina/PI.

Para as alunas, era um dia bastante aguardado em que desejavam estar mais bonitas; de acordo com Maria das Graças Silva, quando foi a data de sua $1^{a}$ eucaristia "[...] cortei meus cabelos de partinha que era pra ficar mais bonita 
[...]”. (SILVA, 2009, p. 13). Quando foi a vez de suas irmãs, Maria Valquíria e Maria do Socorro, realizarem o Sacramento em 1949, elas ganharam vestidos novos dos pais e a data foi registrada em fotografias, as quais foram reproduzidas e dadas de recordação aos parentes e amigos mais próximos ${ }^{10}$.

O ritual da formatura, como a eucaristia, semeia expectativas dentro e fora dos colégios savinianos porque mantém interfaces entre a escola e a sociedade, e, ainda,

Dentre os rituais escolares que preenchem e atribuem significados ao cotidiano escolar, as formaturas merecem destaque, pois, ainda que tenha sofrido modificações resguardaram na contemporaneidade ligações intrínsecas com os significados e simbolismos herdados das solenidades executadas nos séculos anteriores, especialmente no século XX. (SILVA, 2018, p. 03).

Ressaltemos, ainda, que, durante as solenidades de eucaristia, os colégios apontam e exibem o trabalho educacional que estão desenvolvendo. Por meio dos eventos de formatura, são comprovados e atestados a eficiência e a eficácia do ensino e da formação ofertados nos colégios através das concludentes de Cursos que são apresentadas e "entregues" à sociedade.

As formaturas dos colégios savinianos englobavam um conjunto de solenidades similares às dos cursos superiores da atualidade: missa, aulas solenes (aula da saudade), descerramento de quadros (descerramento de placa), colação de grau e festa (baile). Nestas atividades são realizadas "prestações de contas" públicas e individuais aos pais e aos grupos sociais que (re)conhecem e (re)validam a educação dos colégios católicos. As primeiras são feitas pelas instituições de ensino, enquanto a segunda é feita por cada concludente que terá de demonstrar o aprendizado (intelectual, moral, cultural, religioso etc.) obtido durante os anos de estudo. Isso posto, as formaturas se apresentam como exortação pública para que os colégios savinianos - e demais instituições de ensino - tenham que validar continuamente suas ações e práticas educativas, sejam estas pertinentes ao setor pedagógico sejam inerentes as demais áreas educacionais ou não.

10 Produzir fotografias de eventos considerados importantes e entregar como recordação, em geral, com uma dedicatória, era uma prática comum na primeira metade do século XX, quando a revelação fotográfica custava caro e era inacessível para grande maioria da população brasileira. 
Nesse interstício é interessante recordar o contexto histórico em que as formaturas se consolidaram como rituais escolares no Brasil, pois

O republicanismo no Brasil se utilizou também dos ritos escolares para exaltar as conquistas do novo regime, assim, transformar conquistas escolares em eventos públicos torna-se uma estratégia de fomentar a posição dos grupos dirigentes e uma prática social, pois desperta em todos os cidadãos o desejo de conquistar a ascensão social, uma posição social mais elevada e demonstra essa possibilidade através da dedicação aos estudos. (SILVA, 2018, p. 04).

Nos rituais acontecem interfaces entre colégios católicos e parcela de integrantes da sociedade (utilizando metáforas e simbologias). São momentos programados, limitados e organizados, em que há "pequenos encontros" e, por vezes, trocas de experiências, porque são instantes de "demonstração" e visibilidade para ambos os grupos: colégios católicos e grupos sociais.

\section{Considerações finais}

Observar aspectos da rotina dos colégios savinianos piauienses vigentes no século XX, na parcela de tempo em que estes estabelecimentos educavam exclusivamente mulheres, denota-se (dentre outros) as origens de por que eles desfrutam de ampla respeitabilidade na sociedade local e regional: seja pela qualidade do ensino ofertado seja pela inserção social dos discentes após a conclusão dos estudos, ou mesmo pelas teias de relações sociais e capital social e cultural mobilizadas pelos alunos e ex-alunos oriundos dessas instituições escolares.

A organização da rotina escolar produziu uma cultura escolar sólida, articulada, intensa, complexa e arraigada nas alunas, cujas teias extrapolam os limites do espaço e dos tempos escolares, perpetuando-se para além da temporalidade e do lugar dos colégios savinianos. Isso permitiu que esta cultura pudesse se reinventar e reproduzir-se com e através das ex-alunas, de modo a perenizar os ensinamentos obtidos nos estabelecimentos escolares, principalmente, os de base moral e cristão. 


\section{REFERÊNCIAS}

BURKE, P. O historiador como colunista: ensaios da Folha. Rio de Janeiro: Civilização Brasileira, 2009.

CASTRO, A. L. de. (Dona Lili). Entrevista concedida a Samara Mendes Araújo Silva em 20 de fevereiro de 2010, na cidade de Teresina, PI.

COLÉGIO SAGRADO CORAÇÃO DE JESUS. Estatutos e Regras para as Educandas do Collegio Dirigidos pelas Irmãs dos Pobres de S. Catharina de Sena, s.d.

RITO. In: Dicionário eletrônico Houaiss da Língua Portuguesa, 3.0, 2009, não p.

GINÁSIO NOSSA SENHORA DAS GRAÇAS. Regimento Interno do Ginásio Nossa Senhora das Graças. Parnaíba - Piauí, 1962. (mimeo).

JACOBINO, J. M. de O. Entrevista concedida a Samara Mendes Araújo Silva em 10 de fevereiro de 2006.

JULIA, D. A cultura escolar como objeto histórico. Revista Brasileira de História da Educação, n. 1, jan./jun. 2001, p. 09-43.

LEAL, E. M. E. Entrevista concedida a Samara Mendes Araújo Silva em 6 de fevereiro de 2006.

RODRIGUES, E. de M. Entrevista concedida a Samara Mendes Araújo Silva em 13 de julho de 2008, na cidade de Simplício Mendes, PI.

SEGALEN, M. Ritos e rituais contemporâneos. Rio de Janeiro: FGV Editora, 2002.

SILVA, M. das G. R. de S. Entrevista concedida a Samara Mendes Araújo Silva em 13 de outubro de 2009, na cidade de Teresina, PI.

SILVA, S. M. A. Educar Crianças e Jovens à Luz da Fé e Cultura: as instituições escolares confessionais católicas na sociedade piauiense (1906 a 1973). 2010. Tese (Doutorado em Educação Brasileira) - Universidade Federal do Ceará, Fortaleza, 2010.

SILVA, S. M. A. Emoldurando Histórias e Memórias: quadros de formaturas nos colégios católicos brasileiros no Século XX. In: CONGRESO IBEROAMERICANO DE HISTÓRIA DA EDUCAÇÃO, 13., 2018. Anais... SUHE - Sociedade Uruguaia de História da Educação: Montevidéu/Uruguai, 2018.

Texto recebido em 27 de março de 2018. Texto aprovado em 18 de maio de 2018. 